progress in science, and on the relation between science and technology in general.

In outlining his academic career, and his contacts with his teachers and colleagues, Casimir has to refer to the state of physics during that period, and to provide the background he includes a chapter on the development of physics. This is a very brief summary, naming the salient steps rather than trying to explain them; this approach can be defended since the reader cannot expect to be taught the whole of modern physics incidentally. Three appendices, however, give more detail for the physicist reader.

The introduction says ". . . I have tried to write about people I met and knowledge I gained rather than about myself"
Casimir faithfully carries out this intention and keeps himself in the backgrond. But on finishing the book, we feel we have got to know and like him. His life is undramatic, as I have said, but we see his views and his principles emerge from the narrative and, occasionally, his rather puckish sense of humour. And we know what it felt like to be a physicist in the exciting days of the beginning of quantum mechanics.

The title Haphazard Reality evidently relates to the statistical nature of modern physics; it is, perhaps, also meant to hint at important chance influences in Casimir's own life.

Sir Rudolf Peierls is Emeritus Professor of Theoretical Physics at the University of Oxford.

\section{Breadth and depth of plant carbohydrates}

\section{P.H. Rubery}

\section{Encyclopedia of Plant Physiology, Vols}

13A and 13B. Vol. 13A Intracellular

Carbohydrates, Vol. 13B Extracellular

Carbohydrates.

Edited by F.A. Loewus and W. Tanner.

Springer-Verlag: 1982. Vol. 13A, pp.918,

DM298, \$132. Vol. 13B, pp.769,

DM268, \$125.

THESE two, large, multi-author volumes ( 1,700 pages in all) are divided for convenience by the plasma membrane. They deal, from monomer to polymer, with the biochemistry and selected physiological aspects of, respectively, intra- and extracellular carbohydrates (interpreted to include glycoconjugates and hydrophobic wall components). Coverage of carbohydrate metabolism as such is mostly concerned with aspects of biosynthesis and early committed steps in degradation; thus glycolysis and photosynthetic carbon pathways are to be found in other parts of the Encyclopedia. Also, it is disappointing to find little explicit treatment of recent methodological developments in the structural analysis of polysaccharides.

Volume 13B is divided into sections on the cell walls of higher plants ( $270 \mathrm{pp}$.) and of algae and fungi (200 pp.), carbohydrate secretion (100 pp:), and surface recognition phenomena (100 pp.). Each volume has its own author and subject index which, however, lack crossreferences between the two books.

As one would expect, the wellresearched core topics such as sucrose, starch, glycoproteins (figuring in both volumes) and cell walls are thoroughly covered in authoritative reviews similar to those found in other recent encyclopaedic publications such as the Comprehensive Treatise on Plant Biochemistry (reviewed in Nature 299, 762; 1982). Although many of these chapters retain a freshness of approach - evident, for example, in the intelligent, analytical and sceptical account of starch storage (Chapter 20 in Vol. 13A) - a degree of dullness and overkill has crept in. Thus the first four chapters of Vol. 13B, on macromolecular structure and biophysical aspects of higher plant cell walls, are little more than short, overlapping summaries and would have benefited both from some expansion and from the editorial wielding of Occam's Razor.

For me, much of the value of publications such as these lies in the crossfertilization which can result when updated archival material and less-familiar and lessdeveloped topics, such as algal autolysines (Vol. 13B), are brought together within the same covers. Collation of scattered data and their integration in a contemporary context is one function which is well performed in the accounts of glycoproteins, steryl glycosides and non-starch reserve polysaccharides. There are also numerous contributions, such as those dealing with sugar alcohols and nectar secretion, which reveal the importance and fascination of areas sometimes (unjustly) regarded as obscure and prosaic. The chapters dealing with carbohydrate transport (Vol. 13A) and with cell surface phenomena (Vol. 13B), including plantpathogen interactions, are particularly successful and illustrate the importance of including functional aspects to maintain the balance of a work of this sort.

Perhaps when the third series of the Encyclopedia is published sometime in the next millennium, the mechanism of cellulose microfibril deposition and other celebrated puzzles - which are brought out explicitly or, unfortunately more often, implicitly by the current authors will be a little nearer elucidation. In the meantime, these books will be generally invaluable sources of information and inspiration for research work and advanced teaching.

P.H. Rubery is a Lecturer in Biochemistry at the University of Cambridge.

\section{Angles on creativity}

\section{Morris Kline}

Geometrical Investigations Illustrating

the Art of Discovery in the

Mathematical Field.

By John Pottage.

Addison-Wesley: 1983. Pp.480. \$35.95, £26.95.

THE ART of discovering mathematical theorems, to say nothing about proof, has caught the interest of several authors. Some of the resulting books have treated the art in a discursive form and so have failed to pin down the helpful steps such as tackling simple cases first, generalizing on simpler cases, testing hypotheses through comparison with related situations - for example using polygons to suggest a result desired for a circle, which loosely described is an infinite-sided polygon - the use of analogy and other techniques. A few books, notably those of George Polya, have been more specific in their suggestions.

Creativity in mathematics can rarely be the outcome of a chance discovery or plain hard work as Gauss and Einstein very modestly declared. Creation involves groping, blundering, conjecturing, chance associations, experimentation and hypothesizing. It also calls for mental qualities of imagination, insight, intuition, divination, curiosity, hard work, patience, luck and even an aesthetic sense. Asking the right question is another feature of the process; originality, depth and breadth are marks of worth. It is not divine revelation, though the creative mind may at times seek to see itself enshrined as such after the act of creation.

John Pottage is realistic. Though a few Einsteins may have possessed some genius, almost all mathematicians must and do use the down-to-earth methods of creation or discovery treated and exemplified by Pottage. He is specific in his examples of discovery and his primary aim is to inform the layman and to teach teachers how to help students discover. He rightly opposes the rule-of-thumb procedures for learning mathematics or facing students with a correct theorem and a deductive proof as a fait accompli. Though he starts with a difficult problem - namely, to find the formula for the perimeter of an ellipse - he considers many simpler geometric problems involving the perimeters, areas and volumes of polygons, polyhedra, circles, spheres, cylinders and cones; by using - as opposed to discussing - some of the techniques mentioned above, he shows how discovery of the correct hypothesis can be reached. Many of his examples involve curvilinear figures. These illustrations of discovery are not simple, yet the questions he raises and the modifications he suggests in order to reach the correct theorem are to the point and clever. No general principles of 